\title{
Terpene based biopesticides as potential alternatives to synthetic insecticides for control of aphid pests on protected ornamentals
}

by Smith, G.H., Roberts J.M. and Pope, T.W.

Copyright, Publisher and Additional Information: This is the author accepted manuscript. The final published version (version of record) is available online via Elsevier.

This version is made available under the CC-BY-ND-NC licence:

https://creativecommons.org/licenses/by-nc-nd/4.0/legalcode

Please refer to any applicable terms of use of the publisher

DOI: https://doi.org/10.1016/j.cropro.2018.04.011

Smith, G.H., Roberts J.M. and Pope, T.W. 2018. Terpene based biopesticides as potential alternatives to synthetic insecticides for control of aphid pests on protected ornamentals. Crop Protection, 110, pp.125-130. 
1 Terpene based biopesticides as potential alternatives to synthetic insecticides

2 for control of aphid pests on protected ornamentals

3

$4 \quad$ Highlights

5 1. Terpene based biopesticides show promise against aphid pests of ornamental crops

6 2. Products tested based on orange oil, Chenopodium ambrosioides extract and neem oil

7 3. Against Myzus persicae, orange oil gave a similar speed of kill to flonicamid

\section{Abstract}

10 Biopesticides based on plant extracts offer a promising alternative to the use of conventional

11 synthetic pesticides. However, biopesticide products must provide acceptable levels of

12 control. To date, few studies have investigated the efficacy of biopesticide products under

13 conditions that reflect commercial practice. Here we report results from three experiments,

14 one completed under glasshouse conditions in 2014 and two completed under polytunnel

15 conditions, in 2015 and 2016, respectively. These experiments tested the efficacy of three

16 terpene based biopesticides used to control two aphid species, peach-potato aphid (Myzus

17 persicae) and melon and cotton aphid (Aphis gossypii), on ornamental crops. The three

18 biopesticide products tested were orange oil (60 grams active ingredient per litre, formulated

19 as a soluble liquid), the essential oil from Chenopodium ambrosioides variety $\mathrm{nr}$.

20 ambrosioides (16.75\% active ingredient, formulated as an oil dispersion) and neem oil (1\%

21 active ingredient, formulated as emulsifiable concentrate). The biopesticides tested were

22 applied as foliar sprays using a water volume of $600 \mathrm{l} / \mathrm{Ha}$ and all experiments were done at

23 Harper Adams University, Shropshire, UK.

25 The biopesticide products tested gave statistically similar levels of control of $M$. persicae

26 populations on pansy plants as the conventional synthetic insecticide flonicamid $(500 \mathrm{~g} / \mathrm{kg}$ 
27 active ingredient, formulated as a wettable granule) and spirotetramat (150 g/l active

28 ingredient, formulated as an oil dispersion). All products reduced numbers of aphids by at

29 least $85 \%$ during the experimental period. Orange oil also gave a similar speed of kill to

30 flonicamid and was faster acting than spirotetramat, two conventional synthetic insecticides

31 that are widely used to control aphid pests of ornamental crops. Against A. gossypii on

32 Hebe, orange oil gave similar levels of control (90\% reduction in aphid numbers) as

33 flonicamid ( $98 \%$ reduction in aphid numbers), when applied with a spray interval of three

34 days (as per label recommendation). The essential oil from Chenopodium ambrosioides

35 variety nr. ambrosioides was not as effective as flonicamid but did significantly reduced (80\%

36 reduction in aphid numbers) numbers of $A$. gossypii on Hebe compared to a water control

37 when applied with a spray interval of five days. Neem oil was not effective against $A$.

38 gossypii. Importantly, there was little evidence of any phytoxicity caused by any of the

39 biopesticide products tested. The potential to use these products as part of an Insecticide

40 Resistance Management (IRM) programme are discussed.

\section{Keywords}

44 Orange oil, Chenopodium ambrosioides variety nr. ambrosioides, neem oil, azadirachtin, 45 Myzus persicae, Aphis gossypii

\section{Introduction}

50 Continued reliance on synthetic pesticides to provide effective control of crop pests, weeds

51 and diseases is under increasing pressure. The number of active ingredients permitted for

52 use in the European Union (EU) has declined from c. 1,000 actives in 1993 to around 250 in

532011 (Chapman, 2014). This decline is largely the consequence of regulatory changes, e.g. 
implementation of EU Regulation 1107/2009 and an associated shift from risk to hazard based assessment of pesticide safety in terms of human health and the environment. There are also financial and time constraints on the development of active ingredients. The cost of bringing a new active ingredient to market has increased from $\$ 152$ million in 1995 to $\$ 256$ million in 2005 (Chapman, 2014) while the time taken to develop and register a new conventional pesticide is now around 10 years (Glare et al., 2012). As a result, while there were around 70 new active ingredients in the development pipeline in 2000 , this number had dropped to 28 in 2012 (Chapman, 2014). These challenges facing the industry are compounded by increasing numbers of cases of pesticide resistance, with over 580 arthropod species being recorded as having developed resistance globally (Sparks and Nauen, 2015).

Biopesticides offer a promising alternative to the use of conventional synthetic pesticides due to reduced risk of resistance developing in pest populations, lower development costs, higher target specificity, lower environmental persistence, and generally improved compatibility with biological controls (Copping and Menn, 2000; Chandler et al., 2011; Hubbard et al., 2014; Seiber et al., 2014). Plant essential oils are synthesised through secondary metabolic pathways and have long been recognised to possess insecticidal and/or repellent properties (Regnault-Roger et al., 2012; Isman, 2016). Although plant essential oils are typically complex mixtures, they are often dominated by two or three chemical compounds that can be usually classified into two chemical groups, terpenes or phenylpropanoids (Edris, 2007; Bakkali et al., 2008; Regnault-Roger et al., 2012).

There are many examples of biopesticides based on terpenes, including orange or citrus oils, essential oil derived from Chenopodium ambrosioides variety nr. ambrosioides (Chenopodiaceae) and neem extracts. Orange or citrus oils include $d$-limonene as the major component (Hink and Fee, 1986) and are known to be toxic to a wide range of insect pest species (Sheppard 1984; Hink and Fee, 1986; Karr and Coats 1988; Hollingsworth, 2005; 
82 Raina et al., 2007). Products based on orange or citrus oils work through contact as well as, in some cases, fumigation action. The essential oil derived from Chenopodium ambrosioides variety nr. ambrosioides L., consists of a mixture of 14 monoterpenes and is known to be toxic to a range of insect and mite pest species (Chiasson et al., 2004a,b; Cloyd and Chiasson, 2007). Finally, oil extracted from Azadirachta indica A. Juss. (neem) seeds includes, as the major compound, azadirachtin A (a triterpene), which has been shown to have antifeedant and repellent properties as well as inducing sterility in insects, such as the peach-potato aphid (Myzus persicae (Sulzer)) (Mordue (Luntz) et al., 1996; Chaudhary et al., 2017). Although biopesticides based on plant essential oils have previously been shown to have insecticidal effects, their modes of action are poorly understood. The few studies so far completed suggest that plant essential oils are cytotoxic and/or neurotoxic (Pavela and Benelli, 2016), but further work is required in this area. It is also possible that any insecticidal effects observed are the consequence of synergy between different plant essential oils that have differing modes of action. A review of the biological effects of plant essential oils is provided by Bakkali et al. (2008).

Around 100 species of aphid are considered to be agricultural pests of a wide range of crops (van Emden and Harrington, 2007). Two of the most important aphid pest species are $M$. persicae and the melon and cotton aphid (Aphis gossypii Glover) due to the wide range of crops that they may infest and their ability to develop resistance to conventional synthetic insecticides, such as carbamates (e.g. Furk and Hines, 1993; Foster and Blackshaw, 2012), pyrethroids (e.g. Marshall et al., 2012; Foster and Blackshaw, 2012) and neonicotinoids (Bass et al., 2011; Herron and Wilson, 2011).

Both M. persicae and A. gossypii are important pests of ornamental crops (Alford, 2003), where they present a major challenge to growers due to a lack of tolerance to damage and difficulty in achieving effective control using available conventional synthetic insecticides. 
109 Despite increasing interest in, and availability of, biopesticides few studies have investigated

110 the efficacy of biopesticide products relative to currently used conventional synthetic

111 insecticides under conditions that reflect commercial practice. This study investigates the

112 potential of three terpene based biopesticides for the control of M. persicae and A. gossypii

113 on protected ornamental crops.

114

115

\section{Materials and methods}

Insects

119 A population of a single clone of $M$. persicae, known to be resistant to pyrethroid and 120 carbamate insecticides, was maintained on pak choi (Brassica rapa L.) seedlings prior to use 121 in experiments. Aphis gossypii were collected from a commercial ornamentals nursery and maintained on cotton seedlings (Gossypium hirsutum L.) prior to use in experiments. Both aphid populations were maintained in fine mesh insects cages of size $47.5 \times 47.5 \times 47.5 \mathrm{~cm}$

124 (BugDorm, MegaView Science, Taichung City, Taiwan). Plants were changed each week and fresh plants infested with aphids taken from the discarded plants. Insect cages were placed in controlled environment rooms (Weiss Technik UK Ltd, Ebbw Vale, UK) set to $20^{\circ} \mathrm{C}, 60 \%$ relative humidity and 16:8 (light:dark) hours.

128

129

Plants

130

Pansy (Viola x wittrockiana var. Lubega F1 Mix) and Hebe 'Purple Pixie' plug plants were planted into $9 \mathrm{~cm}$ diameter pots in May in each year of the project. Pansy plants were potted into a peat based growing medium (M3 Pot/Bedding Compost, Levington, Frimley, UK) while Hebe plants were potted into a soil based growing medium (John Innes No. 2, J Arthur

134 Bower's, Lincoln, UK). Pots were placed into a ventilated polytunnel and stood on capillary 135 matting to allow for watering. Plants were grown on until they had begun to flower 
136 (July/August) before being transferred to a ventilated glasshouse compartment (pansy plants)

137 or ventilated polytunnel (Hebe plants).

Infesting plants with aphids

140 A small number of pansy plants were placed into the insect cages in which M. persicae were

141 reared and a similar number of Hebe plants were placed into the insect cages in which $A$.

142 gossypii were reared. Plants were placed close together so that aphids were able to colonise

143 the pansy and Hebe plants. Once aphid populations had become established on pansy and

144 Hebe plants, completing at least two generations, these plants were then used to infest the remaining pansy and Hebe plants. The remaining plants were infested by carefully placing aphid infested leaves of the same plant species onto a previously uninfested plant. In this way each plant was infested with approximately 10 mixed age aphids. Aphid populations were allowed to establish for two weeks before the start of the experiment.

Treatments

151 Two conventional insecticides were used in this study, flonicamid (Mainman) and 152 spirotetramat (Movento) (see Table 1). Flonicamid works primarily through ingestion and 153 inhibits aphid feeding. Spirotetramat, also works mainly through ingestion, and is an acetyl154 CoA carboxylase inhibitor. Both insecticides are widely used for control of aphids on ornamental crops. The three biopesticide products are based on plant essential oils (see Table 1). Azadirachtin $A$ is obtained from neem seeds (Azadirachta indica) and is formulated as an emulsifiable concentrate containing $1 \%$ azadirachtin A. Chenopodium ambrosioides variety nr. ambrosioides, variously known as wormseed, Jesuit's tea or Mexican-tea is formulated as an oil dispersion containing $16.75 \%$ of the essential oil, which is composed of a mixture of 14 monoterpenes. Orange oil is formulated as soluble liquid containing $60 \mathrm{~g} / \mathrm{l}$ of the active ingredient of which $d$-limonene is the major component. 
164 Treatments and a water control were applied using an Oxford Precision Sprayer (MDM

165 Engineering Ltd, Bristol, UK) fitted with a hollow cone nozzle (HC/1.74/3, Hypro EU Ltd, 166 Cambridge, UK) delivering a droplet size of 200-300 $\mu \mathrm{m}$. Spray applications were made using 167 three 3 bar pressure. The concentration of each product used was recommended by the manufacturer (see Table 1) and water volumes were standardised at $600 \mathrm{l} / \mathrm{Ha}$.

171 Experimental design

172 Individual plots were created on benching within a glasshouse compartment or polytunnel 173 using panels of horticultural fleece fastened to a wooden frame to create open fronted cages. 174 Each side of the cage used a panel of horticultural fleece on each side of the frame in order 175 to create two layers of fleece between each adjacent cage. Plots were $0.5 \mathrm{~m}$ wide, $0.75 \mathrm{~m}$ deep and $0.75 \mathrm{~m}$ high and plants were positioned as described in the centre of each plot and so at least $10 \mathrm{~cm}$ away from the walls of the cage. The open top and front of each cage allowed for ventilation and provided access for sampling and treatment application but importantly reduced the movement of aphids between plots. Furthermore, as some components of the biopesticide products tested are volatile the two layers of horticultural fleece minimised airflow between plots. In order to prevent spray drift between plots or spray deposits coming into contact with the wooden frame or horticultural fleece panels, solid plastic screens were placed around the perimeter of each plot during spray application. Benches were lined with capillary matting to allow for watering. A total of nine aphid infested plants, arranged in three rows of three, were placed in each plot. Each of the following three experiments used a randomised block design with each treatment replicated six times:

188 Experiment 1 - efficacy of biopesticides to control $M$. persicae on pansy plants under glasshouse conditions. This experiment tested the relative efficacy of the three terpene based 190 biopesticide products compared with two synthetic insecticides as well as a water control (see 
191 Table 1). In total, four applications of each treatment and the water control were applied;

192 applications were made at intervals of seven days.

Experiment 2 - as described for Experiment 1 but controlling A. gossypii on Hebe plants under polytunnel conditions.

Experiment 3 - efficacy of biopesticides to control A. gossypii on Hebe plants under polytunnel conditions. This experiment tested the relative efficacy of three terpene based biopesticide products compared with the synthetic insecticide flonicamid as well as a water control. Unlike in Experiment 2, where the number of applications and interval between each application was standardised between each treatment, here the total number of applications and interval between applications of each treatment over the 14 day experimental period was specified by each manufacturer (see Table 1). As a result the number of applications ranged from between one for flonicamid, made at the start of the experimental period, and five for Biopesticide 3 (orange oil) where applications were made at intervals of three days.

\section{Assessments}

Assessments of aphid numbers were done immediately before the first treatment application, three and six days after the first treatment application and then weekly intervals over the remainder of the experimental period. For each assessment of aphid numbers, all plants were assessed, recording aphid numbers on the central/dominant stem of the plant. In each case recording numbers of live aphids, of the species of interest, on the leaves, flowers and stems.

213 The presence of any other pests was also recorded along with the presence of any natural enemies. Evidence of phytotoxicity caused by treatment application was also recorded each time aphid numbers were recorded. Phytotoxicity assessments followed those developed by the European and Mediterranean Plant Protection Organisation (guideline PP1/135). On each assessment date all plants were assessed for evidence of inhibition of plant growth, thinning of the plant, modification in plant colour (including both leaves and flower petals), evidence of 
necrosis and deformations. Assessments were made by visually comparing the plants which had been treated with a conventional synthetic insecticide or biopesticide product with control plants. Finally, the temperature during each experiment was recorded using datalogger (iButtons, HomeChip Ltd, Milton Keynes, UK).

\section{Statistical analyses}

All statistical analyses were performed using the statistics program Genstat $17^{\text {th }}$ Edition (Genstat, VSN International Ltd, Hemel Hempstead, UK). Each experiment was set out in a randomised complete block design. Blocking was used to take into account any variability in environmental conditions along the length of the polytunnel or glasshouse compartment with increasing distance from the entrance. Weekly count data were analysed independently using analysis of variance (ANOVA) with $\operatorname{Ln}(\mathrm{c}=1)$ transformation of raw data. Individual comparisons between treatments were made using Tukey's HSD test.

\section{Results}

Results and statistical analyses from Experiment 1 are summarised in Table 2. All products tested had reduced numbers of $M$. persicae to zero, or close to zero, in each plot by the end of the experimental period. Statistical analysis of the $\operatorname{Ln}(c=1)$ transformed aphid count data shows that there was no significant difference in numbers of $M$. persicae between treatments before the first spray application (mean aphid numbers per plot for each treatment and the water control were between 20 and 32), but that there was a strong $(P<0.001)$ treatment effect for all assessments completed after this; i.e. from three days after the first the spray application. No block effects were recorded on any of the assessment dates.

Individual comparisons between treatment means (indicated by Tukey's HSD test) showed that numbers of $M$. persicae in plots treated with either Biopesticide 3 (active ingredient 
orange oil) or the conventional insecticide Mainman (active ingredient flonicamid) were significantly lower than in plots treated with the water control three days after the first spray application. Of the other products tested, numbers of $M$. persicae in plots treated with Movento (active ingredient spirotetramat), Biopesticide 1 (active ingredient azadirachtin A) and Biopesticide 2 (active ingredient Chenopodium ambrosioides extract) were significantly lower than in plots treated with the water control 6, 13 and 21 days after the first spray application, respectively. There were no statistical differences between the numbers of aphids recorded in plots treated with any of the conventional insecticides or biopesticides tested from 21 days after the first spray application.

No effects on plant health (determined by assessments of plant growth, thinning of the plant, evidence of necrosis and deformations) were recorded as a result of any treatment application. Some slight colour changes to leaves and/or flowers were noted for all products tested but were most apparent for Biopesticide products 1 ( $<5 \%$ of flowers and $<1 \%$ of leaves showing a slight colour change) and $3(<5 \%$ of flowers and $<1 \%$ of leaves similarly showing a slight colour change) after each of the first three spray applications. There was no evidence of any colour change to flowers or leaves after the fourth spray application. Each product was applied when temperatures were between 16.5 and $18.6^{\circ} \mathrm{C}$. There was no evidence of any non-target effects of the products tested in this experiment, no other insects were recorded on the plants throughout the assessment period.

Results and statistical analyses from Experiment 2 are summarised in Table 3. Of the products tested, only the conventional insecticide Mainman had reduced numbers of $A$. gossypii to close to zero in each plot by the end of the experimental period. The conventional insecticide Movento and Biopesticide products 1, 2 and 3 had reduced aphid numbers by 80 , 0,44 and $0 \%$, respectively, over the same period. Statistical analysis of the transformed aphid count data showed that there was no difference in numbers of $A$. gossypii between treatments and the water control before the first spray application (mean aphid numbers per 
275 plot for each treatment and the water control were between 62 and 92). Statistical

276 differences were only apparent after plots had received three spray applications, i.e. 21 days

277 after the first spray application. No block effects were recorded on any of the assessment

278 dates.

Individual comparisons between treatment means showed that numbers of $A$. gossypii in

281 plots treated with the conventional insecticide Mainman were significantly lower than in plots treated with the water control 21 days after the first spray application, by which time three spray applications had been completed. Of the other products tested, numbers of $A$. gossypii were significantly lower in plots treated with Movento compared with the water control. This difference was, however, only recorded on the final assessment date, after four spray applications had been applied. Numbers of $A$. gossypii in plots treated with Movento did not differ from numbers of aphids recorded in plots treated with any of the biopesticide products. None of the biopesticide products tested significantly reduced numbers of $A$. gossypii relative to the water control.

No effects on plant health (determined by assessments of plant growth, thinning of the plant, modification in plant colour (including both leaves and flower petals), evidence of necrosis and deformations) were recorded as a result of any treatment application. Each product was applied when temperatures were between 17.0 and $25.0^{\circ} \mathrm{C}$. There was no evidence of any non-target effects of the products tested in this experiment. Aphid parasitoids (Aphidius spp.), seen as mummified aphids, were recorded at very low numbers ( $<1$ per plant) in all plots regardless of the treatment applied.

Results and statistical analyses from Experiment 3 are summarised in Table 4. Of the products tested, all except Biopesticide 1 had reduced $A$. gossypii to low numbers in each plot by the end of the experimental period. The conventional insecticide Mainman and 302 Biopesticide products 2 and 3 had reduced aphid numbers by 98,81 and $90 \%$, respectively, 
over the same period. Statistical analysis of the transformed aphid count data showed that there was no difference in numbers of $A$. gossypii between treatments and the water control before the first spray application (mean aphid numbers per plot for each treatment and the water control were between 28 and 32) and statistical differences were only apparent 14 days after the first spray application. No block effects were recorded on any of the assessment dates.

Individual comparisons between treatment means shows that numbers of $A$. gossypii in plots treated with either biopesticide products 2 or 3 , or the conventional insecticide flonicamid, were significantly lower than in plots treated with the water control 14 and 20 days after the first spray application. Fourteen days after the first spray application plots had received one application of Mainman, three applications of Biopesticide 2, and five applications of Biopesticide 3. Twenty days after the first spray application numbers of $A$. gossypii in plots treated with Mainman were significantly lower than in plots treated with Biopesticides 1 or 2 but were not statistically different from numbers in plots treated with Biopesticide 3.

No effects on plant health (determined by assessments of plant growth, thinning of the plant, modification in plant colour (including both leaves and flower petals), evidence of necrosis and deformations) were recorded as a result of any treatment application. Each product was applied when temperatures were between 20.6 and $31.1^{\circ} \mathrm{C}$. As for Experiment 2, there was no evidence of any non-target effects of the products tested in this experiment. Aphid parasitoids (Aphidius spp.), seen as mummified aphids, were recorded at very low numbers $(<1$ per plant) in all plots regardless of the treatment applied.

\section{Discussion}


330 Biopesticides based upon plant extracts have a number of benefits when compared to their 331 conventional synthetic counterparts, including: little to no toxic residues, increased operator safety, reduced development and production costs, multiple modes of action, and compatibility with existing spray technologies (Hajek, 2004; Chandler et al., 2011; Pavela and Benelli, 2016). However, the use of biopesticides based on plant extracts can also have a number of disadvantages compared to conventional synthetic pesticides, including shorter persistence and potential phytotoxic effects (Chandler et al., 2011). These disadvantages typically mean that most biopesticides based on plant extracts are not as effective as conventional synthetic pesticides and as a result are not suited for use as stand-alone treatments, but may form an important part of an Integrated Pest Management (IPM) programme.

This study tested the efficacy of three terpene based biopesticide products based on orange oil, the essential oil from Chenopodium ambrosioides variety nr. ambrosioides or azadirachtin A from neem oil, applied under commercial conditions against the aphid pests M. persicae and A. gossypii. Results indicate that these products may be used both as part of an IPM programme and, in some cases, may be used as a stand-alone treatment against these pests. All three biopesticide products were notable for their overall efficacy against $M$. persicae and, in the case of the orange oil based product, for its speed of kill against this pest. The rapid speed of kill seen following application of the orange oil based product is most likely due to its combined contact and possible fumigant action (Raina et al., 2007). Indeed, statistically significant reductions in M. persicae populations on pansy plants were seen just three days after application of this biopesticide product, similar to the results for the conventional synthetic insecticide flonicamid and faster than the reductions observed for spirotetramat. As both flonicamid and spirotetramat are widely used to control aphid pests of ornamental crops the speed of kill reported here for orange oil, after a the first application, is 356 likely to be acceptable to growers wishing to control M. persicae. 
358 The biopesticide products based on the Chenopodium ambrosioides extract or azadirachtin

359 A were slower acting, with statistically significant reductions in M. persicae populations on

360 pansy plants only seen 21 and 13 days after the first spray application, respectively.

361 Although the mode of action of the essential oil of Chenopodium ambrosioides is not known,

362 neem based biopesticides are known to be slower acting, displaying antifeedant and

363 repellent properties as well as inducing sterility in M. persicae (Mordue (Luntz) et al., 1996;

364 Chaudhary et al., 2017).

365

366 The overall efficacy against M. persicae of all three biopesticide products, after four spray

367 applications had been completed over a four week period, was not statistically different to

368 the conventional synthetic insecticides used. The biopesticide based on orange oil reduced

369 populations of $M$. persicae by $85 \%$, the product based on the essential oil from

370 Chenopodium ambrosioides by $87 \%$ and the product based on azadirachtin A by $86 \%$. By

371 comparison the conventional synthetic insecticides Mainman and Movento reduced aphid

372 numbers by 99 and $97 \%$, respectively, in the same experiment. Results presented here

373 appear to be broadly similar to those reported by a Chiasson et al. (2004) who tested the

374 efficacy of a biopesticide product based on the essential oil from Chenopodium

375 ambrosioides against $M$. persicae on Verbena. This study used a similar methodology, but

376 found a biopesticide product based on this essential oil to be more effective against this pest

377 than a biopesticide based on azadirachtin A and similarly effective to an insecticidal soap

378 (potassium salts of fatty acids with $0.2 \%$ pyrethrins).

380 Speed of kill and overall efficacy was reduced when these biopesticides were applied 381 against $A$. gossypii on Hebe. This may indicate that the complex architecture of this crop 382 limited spray coverage. Good spray coverage is essential for biopesticides that display 383 contact activity (Copping and Menn, 2000). Evidence for the importance of spray coverage 384 can be seen most notably by the improved control of $A$. gossypii when the biopesticide 385 based on orange oil was applied to crops every three days in Experiment 3, as 
recommended by the manufacturer, compared with every seven days, as in Experiment 2. Indeed, when applied following label recommendations the biopesticide based on orange oil gave a statistically similar level of control as the conventional synthetic insecticide Mainman. The biopesticide based on the essential oil from Chenopodium ambrosioides was less effective, but did significantly reduce populations of $A$. gossypii compared to the water control. The biopesticide based on azadirachtin A was ineffective against this pest.

The requirement for good spray coverage and repeated applications of the biopesticide products tested here to achieve effective control of crop pests highlights the need for developments in biopesticide application techniques. For example, current standard practice in the protected ornamentals industry is to use spray lance or pistol systems with extremely high water volumes of $750-5,000$ L/ha to apply pesticides to crops (Buxton, 2012). With such high water volumes the time taken to apply pesticides is increased meaning that labour costs increase. Furthermore, spray lance or pistol systems typically do not provide good spray coverage of the underside of leaves (Derkson et al., 2008). Development and adoption of more efficient and effective spray application techniques such as booms sprayer systems, electrostatic sprayers, ultra-low volume (ULV) sprayers or gantry sprayer systems are likely to improve both the efficacy and cost-effectiveness of biopesticides.

It has been noted that the essential oils that are most efficacious against pests are often the most phytotoxic (Isman, 2000). While it is true that slight colour changes to petals and leaves of pansy plants was most obvious following application of the biopesticide based on orange oil, and to a lesser extent neem oil, the observed symptoms were rare and slight, with less than $1 \%$ of leaves affected. Nonetheless, great care is required to avoid phytotoxic effects when using biopesticides based on essential oils. Besides any phytotoxic effects resulting from the use of plant essential oil based biopesticides it is also important to consider that very little is known with regards to crop safety (Regnault-Roger et al., 2012), requiring further work to comply with stringent legislation before commercialisation. Similarly, there is 
414 comparatively little published information on the side-effects of plant essential oil based

415 biopesticides.

416

417 Results presented herein show that the three terpene based biopesticides have the potential

418 to reduce reliance on conventional synthetic pesticides by providing effective control of key

419 aphid pests of ornamental plants. This is particularly important as M. persicae and A.

420 gossypii have repeatedly developed resistance to conventional synthetic insecticides, such

421 as pyrethroids, carbamates and neonicotinoids (e.g. Furk and Hines, 1993; Bass et al.,

422 2011; Herron and Wilson, 2011; Foster and Blackshaw, 2012; Marshall et al., 2012, 2012).

423 Biopesticide products may, therefore, form an important component of an Insecticide

424 Resistance Management (IRM) programme to prevent or delay future cases of insecticide

425 resistance from developing. This may be achieved by alternating use of biopesticide

426 products with conventional synthetic insecticides and thereby rotating the modes of action

427 used to control these pests (Sparks and Nauen, 2015).

428

429 Acknowledgements

430 We are grateful to Dr Stephen Foster for supplying Myzus persicae and Selchuk Kurtev for

431 supplying Aphis gossypii used to establish cultures at Harper Adams University. We are also

432 grateful to The Bransford Webbs Plant Company for supplying the plants used in this study

433 and to Dr Fabio Veronesi for statistical advise in completing this work. This work was funded

434 by AHDB Horticulture [Project number CP 124].

435

436 References

437 Alford, D. V. (2003) A colour atlas of pests of ornamental trees, shrubs and flowers. Timber

$438 \quad$ Press, Oregon, U.S.A. 448 pp.

439 Bakkali, F., Averbeck, S., Averbeck, D. and Idaomar, M. (2008) Biological effects of essential

$440 \quad$ oils - a review. Food and Chemical Toxicology. 46: 446-475. 
Bass, C., Puinean, A. M., Andrews, M., Cutler, M., Daniels, M., Elias, J., Paul, V. L.,

442 Crossthwaite, A. J., Denholm, I., Field, L. M., Foster, S. P., Lind, R., Williamson, M. S. and Slater, R. (2011) Mutation of a nicotinic acetylcholine receptor $\beta$ subunit is associated

with resistance to neonicotinoid insecticides in the aphid Myzus persicae. BMC Neuroscience. 12: 51.

Buxton, J. (2012) Improving the efficiency of spray application for protected ornamental crops: a study of current spraying methods and novel spraying technologies. $A H D B$ Horticulture, Final Report. $21 \mathrm{pp}$.

Chaudhary, C., Kanwar, R. K., Sehgal, A., Cahill, D. M., Barrow, C. J., Sehgal, R. and Kanwar, J. R. (2017) Progress on Azadirachta indica based biopesticides in replacing synthetic toxic pesticides. Frontiers in Plant Science. 8: 610.

Chandler, D., Bailey, A. S., Tatchell, G. M., Davidson, G., Greaves, J. and Grant, W. P. (2011) The development, regulation and use of biopesticides for integrated pest management. Philosophical Transactions of the Royal Society B. 366: 1987-1998.

Chapman, P. (2014) Is the regulatory regime for the registration of plant protection products in the EU potentially compromising food security? Food and Energy Security. 3: 1-6.

Chiasson, H., Bostanian, N. J. and Vincent, C. (2004a) Acaricidal properties of a Chenopodium-based botanical. Journal of Economic Entomology. 97: 1373-1377.

Chiasson, H., Vincent, C. and Bostanian, N. J. (2004b) Insecticidal properties of a Chenopodium-based botanical. Journal of Economic Entomology. 97: 1378-1383.

Copping, L. G. and Menn, J. J. (2000) Biopesticides: a review of their action, applications and efficacy. Pest Management Science. 56: 651-676.

Cloyd, R. A. and Chiasson, H. (2007) Activity of an essential oil derived from Chenopodium ambrosioides on greenhouse insect pests. Journal of Economic Entomology. 100: 459466.

Derkson, R. C., Frantz, J., Ranger, C. M., Locke, J. C., Zhus, H. and Krause, C. R. (2008) Comparing greenhouse handgun delivery to poinsettias by spray volume and quality. Transactions of the American Society of Engineers (ASABE). 51: 27-33. 
Edris, A. E. (2007) Pharmaceutical and therapeutic potentials of essential oils and their individual volatile constituents: a review. Phytotherapy Research. 21: 308-323.

Foster, S. and Blackshaw, R. (2012). Sustaining the effectiveness of new insecticides against aphid pests in the UK. Final report to Defra Project RD-2008-3471 (HDC project FV 344).

Furk, C. and Hines, C.M. (1993). Aspects of pirimicarb resistance in the cotton and melon aphid, Aphis gossypii Glover (Homoptera: Aphidiidae). Annals of Applied Biology. 123, 917.

Glare, T., Caradus, J., Gelernter, W., Jackson, T., Keyhani, N., Köhl, J., Marrone, P., Morin, L. and Stewart, A. (2012) Have biopesticides come of age? Trends in Biotechnology. 30: $250-258$

Herron, G. A. and Wilson, L. J. (2011) Neonicotinoid resistance in Aphis gossypii Glover (Aphididae: Hemiptera) from Australian cotton. Australian Journal of Entomology. 50: 9398.

Hink, W.F. and Fee. B.J. (1986) Toxicity of $D$-limonene, the major component of citrus peel oil, to all life stages of the cat flea, Ctenocephalides felis (Siphonaptera: Pulicidae). Journal of Medical Entomology. 23: 400-404.

Hollingsworth, R.G. (2005) Limonene, a citrus extract, for control of mealybugs and scale insects. Journal of Economic Entomology. 98: 772-779.

Hubbard, M., Hynes, R. K., Erlandson, M. and Bailey, K. L. (2014) The biochemistry behind biopesticide efficacy. Sustainable Chemical Processes. 2:18.

Isman, M. B. (2000) Plant essential oils for pest and disease management. Crop Protection. 19: $603-608$.

Isman, M. B. (2016) Pesticides based on plant essential oils: phytochemical and practical considerations. Medicinal and Aromatic Crops: Production, Phytochemistry, and Utilization. 13-26.

Karr, L. and Coats. J.R. (1988) Insecticidal properties of $D$-limonene. Journal of Pesticide Science. 13: 287-290. 
Marshall, K.L., Moran, C., Chen, Y.Z. and Hwerron, G.A. (2012) Detection of kdr pyrethroid resistance in the cotton aphid, Aphis gossypii (Hemiptera: Aphididae), using a PCR-RFLP assay. Journal of Pesticide Science. 37, 169-172.

Mordue (Luntz), A. J., Nisbet, A. J., Nasiruddin, M. and Walkeriet, E. (1996) Differential thresholds of azadirachtin for feeding deterrence and toxicity in locusts and an aphid. Entomologia Experimentalis et Applicata. 80: 69-72.

Pavela, R. and Benelli, G. (2016) Essential oils as eco-friendly biopesticides? Challenges and constraints. Trends in Plant Science. 12: 1000-1007.

Raina, A., Bland, J., Doolittle, M., Lax, A., Boopathy, R. and Folkins, M. (2007) Effect of orange oil extract on the Formosan subterranean termite (Isoptera: Rhinotermitidae). Journal of Economic Entomology. 100: 880-885

Regnault-Roger, C., Vincent, C. and Arnason, J. T. (2012) Essential oils in insect control: low-risk products in a high-stakes world. Annual Review of Entomology. 57: 405-424. Seiber, J. N., Coats, J., Duke, S. O. and Fross, A. D. (2014) Biopesticides: state of the art and future opportunities. Journal of Agricultural and Food Chemistry. 62: 11613-11619.

Sheppard, D.C. (1984) Toxicity of citrus peel liquids to the house fly and red imported fire ant. Journal of Agricultural Entomology. 1: 95-100.

Sparks, T. C. and Nauen, R. (2015) IRAC: Mode of action classification and insecticide resistance management. Pesticide Biochemistry and Physiology. 121: 122-128.

van Emden, H. F. and Harrington, R. (Eds.) (2007) Aphids as crops pests. CABI Publishing, Wallingford, UK. 752 pp. 
523 Table 1. Products tested in this study. Minimum interval (days) between applications and

524 maximum number of applications permitted within experimental period columns apply only to

525 Experiment 3. For Experiments 1 and 2 a total of four applications of each treatment and the 526 water control were applied with each application made at intervals of seven days.

527

528 Table 2. Effect of treatments on Myzus persicae. Raw data transformed using Ln (c=1) and 529 presented as mean number of aphids/plot. Numbers in a column followed by the same letter 530 are not significantly different at $P<0.05$ based on individual contrasts (Tukey's HSD test).

531 DAIT = Days After Initial Treatment.

532

533 Table 3. Effect of treatments on Aphis gossypii. Raw data transformed using $\operatorname{Ln}(\mathrm{c}=1)$ and 534 presented as mean number of aphids/plot. Numbers in a column followed by the same letter 535 are not significantly different at $P<0.05$ based on individual contrasts (Tukey's HSD test). 536 DAIT = Days After Initial Treatment.

537

538 Table 4. Effect of treatments on Aphis gossypii. Raw data transformed using Ln (c=1) and 539 presented as mean number of aphids/plot. Numbers in a column followed by the same letter 540 are not significantly different at $P<0.05$ based on individual contrasts (Tukey's HSD test). 541 DAIT = Days After Initial Treatment. 


\begin{tabular}{|c|c|c|c|c|c|c|}
\hline Product name & $\begin{array}{l}\text { Active } \\
\text { ingredient(s) }\end{array}$ & $\begin{array}{l}\text { Active ingredient } \\
\text { concentration }\end{array}$ & $\begin{array}{l}\text { Formulation } \\
\text { type }\end{array}$ & Application rate & $\begin{array}{l}\text { Minimum interval } \\
\text { (days) between } \\
\text { applications }\end{array}$ & $\begin{array}{l}\text { Maximum number of } \\
\text { applications permitted within } \\
\text { experimental period }\end{array}$ \\
\hline Mainman & flonicamid & $500 \mathrm{~g} / \mathrm{kg}$ & $\begin{array}{l}\text { wettable } \\
\text { granule }\end{array}$ & $0.14 \mathrm{~kg} / \mathrm{ha}$ & 21 & 1 \\
\hline Movento & spirotetramat & $150 \mathrm{~g} / \mathrm{l}$ & oil dispersion & $0.5 \mathrm{l} / \mathrm{ha}$ & $\mathrm{N} / \mathrm{A}$ & $\mathrm{N} / \mathrm{A}$ \\
\hline Biopesticide 1 & azadirachtin A & $1 \%$ & $\begin{array}{l}\text { emulsifiable } \\
\text { concentrate }\end{array}$ & $\begin{array}{l}0.5 \%(3.0 \mathrm{l} / \mathrm{ha} \\
\text { when applied in } \\
600 \text { I of water/ha) }\end{array}$ & 7 & 2 \\
\hline Biopesticide 2 & $\begin{array}{l}\text { Chenopodium } \\
\text { ambrosioides } \\
\text { extract }\end{array}$ & $16.75 \%$ & oil dispersion & $\begin{array}{l}0.67 \mathrm{v} / \mathrm{v}(4.0 \mathrm{l} / \mathrm{ha} \\
\text { if applied in } 600 \mathrm{I} \\
\text { water/ha) }\end{array}$ & 5 & 3 \\
\hline Biopesticide 3 & orange oil & $60 \mathrm{~g} / \mathrm{l}$ & soluble liquid & $\begin{array}{l}0.4 \%(2.4 \mathrm{l} / \mathrm{ha} \\
\text { when applied in } \\
600 \text { I of water/ha) }\end{array}$ & 3 & 5 \\
\hline
\end{tabular}




\begin{tabular}{|c|c|c|c|c|c|c|}
\hline Product name (active ingredient) & $-1 \mathrm{DAIT}$ & 3 DAIT & 6 DAIT & 13 DAIT & $21 \mathrm{DAIT}$ & 27 DAIT \\
\hline Water control (n/a) & $3.22^{\mathrm{a}}$ & $3.86^{c}$ & $4.14^{c}$ & $3.91^{\mathrm{c}}$ & $4.58^{b}$ & $3.93^{b}$ \\
\hline Movento (spirotetramat) & $3.46^{\mathrm{a}}$ & $3.44^{\mathrm{bc}}$ & $2.12^{\mathrm{ab}}$ & $0.41^{\mathrm{a}}$ & $0.23^{a}$ & $0.38^{a}$ \\
\hline Mainman (flonicamid) & $2.86^{a}$ & $2.19^{\mathrm{ab}}$ & $0.88^{a}$ & $0.30^{\mathrm{a}}$ & $0^{\mathrm{a}}$ & $0.12^{\mathrm{a}}$ \\
\hline Biopesticide 1 (azadirachtin A) & $2.80^{a}$ & $3.39^{b c}$ & $2.85^{\mathrm{bc}}$ & $1.31^{\mathrm{ab}}$ & $0.83^{a}$ & $1.31^{\mathrm{a}}$ \\
\hline Biopesticide 2 (Chenopodium ambrosioides extract) & $2.91^{a}$ & $3.65^{\mathrm{c}}$ & $3.15^{\mathrm{bc}}$ & $2.51^{\mathrm{bc}}$ & $1.03^{a}$ & $0.98^{a}$ \\
\hline Biopesticide 3 (orange oil) & $2.82^{a}$ & $1.49^{a}$ & $1.13^{a}$ & $1.12^{\mathrm{ab}}$ & $1.01^{a}$ & $0.72^{a}$ \\
\hline F value (5 d.f.) & 1.14 & 10.29 & 14.26 & 12.44 & 19.78 & 15.90 \\
\hline Treatment & $(P=$ n.s. $)$ & $(P<0.001)$ & $(P<0.001)$ & $(P<0.001)$ & $(P<0.001)$ & $(P<0.001)$ \\
\hline$F$ value (5 d.f.) & 1.32 & 0.95 & 1.25 & 1.24 & 0.47 & 0.52 \\
\hline Block & $(P=$ n.s. $)$ & $(P=$ n.s. $)$ & $(P=$ n.s. $)$ & $(P=$ n.s. $)$ & $(P=$ n.s. $)$ & $(P=$ n.s. $)$ \\
\hline
\end{tabular}




\begin{tabular}{|c|c|c|c|c|c|c|}
\hline Product name/active ingredient & -1 DAIT & 3 DAIT & 6 DAIT & 13 DAIT & 21 DAIT & 27 DAIT \\
\hline Water control (n/a) & $4.07^{a}$ & $3.83^{a}$ & $3.83^{\mathrm{a}}$ & $4.26^{\mathrm{a}}$ & $4.66^{b}$ & $4.89^{c}$ \\
\hline Movento (spirotetramat) & $4.16^{a}$ & $3.63^{a}$ & $3.41^{\mathrm{a}}$ & $2.97^{a}$ & $2.11^{\mathrm{a}, \mathrm{b}}$ & $2.40^{a, b}$ \\
\hline Mainman (flonicamid) & $4.08^{a}$ & $3.52^{\mathrm{a}}$ & $3.24^{a}$ & $2.23^{a}$ & $0.53^{a}$ & $0.35^{a}$ \\
\hline Biopesticide 1 (azadirachtin A) & $4.39^{a}$ & $3.57^{\mathrm{a}}$ & $3.50^{\mathrm{a}}$ & $3.34^{\mathrm{a}}$ & $3.14^{\mathrm{a}, \mathrm{b}}$ & $3.46^{\mathrm{b}, \mathrm{c}}$ \\
\hline Biopesticide 2 (Chenopodium ambrosioides extract) & $4.20^{\mathrm{a}}$ & $3.12^{\mathrm{a}}$ & $3.23^{a}$ & $3.39^{a}$ & $3.29^{b}$ & $3.23^{b, c}$ \\
\hline Biopesticide 3 (orange oil) & $4.12^{\mathrm{a}}$ & $3.42^{\mathrm{a}}$ & $3.49^{a}$ & $3.44^{\mathrm{a}}$ & $3.33^{b}$ & $3.35^{b, c}$ \\
\hline F value (5 d.f.) & 0.20 & 0.23 & 0.19 & 1.67 & 5.23 & 8.60 \\
\hline Treatment & (P = n.s.) & (P = n.s.) & $(P=$ n.s. $)$ & (P = n.s.) & $(P=0.002)$ & $(P<0.001)$ \\
\hline$F$ value (5 d.f.) & 0.69 & 0.68 & 0.48 & 0.87 & 0.73 & 1.74 \\
\hline Block & $(P=$ n.s. $)$ & $(P=$ n.s. $)$ & (P = n.s. $)$ & $(P=$ n.s. $)$ & (P = n.s. $)$ & $(P=$ n.s. $)$ \\
\hline
\end{tabular}




\begin{tabular}{llllll}
\hline Product name & -1 DAIT & 3 DAIT & 6 DAIT & 14 DAIT & 20 DAIT \\
\hline Water control (n/a) & $3.36^{\mathrm{a}}$ & $2.86^{\mathrm{a}}$ & $2.73^{\mathrm{a}}$ & $2.70^{\mathrm{b}}$ & $3.15^{\mathrm{d}}$ \\
Mainman (flonicamid) & $3.32^{\mathrm{a}}$ & $2.53^{\mathrm{a}}$ & $1.71^{\mathrm{a}}$ & $0.35^{\mathrm{a}}$ & $0.35^{\mathrm{a}}$ \\
Biopesticide 1 (azadirachtin A) & $3.39^{\mathrm{a}}$ & $2.65^{\mathrm{a}}$ & $2.50^{\mathrm{a}}$ & $2.80^{\mathrm{b}}$ & $2.66^{\mathrm{cd}}$ \\
Biopesticide 2 (Chenopodium ambrosioides extract) & $3.43^{\mathrm{a}}$ & $1.63^{\mathrm{a}}$ & $2.35^{\mathrm{a}}$ & $1.37^{\mathrm{a}}$ & $1.67^{\mathrm{bc}}$ \\
Biopesticide 3 (orange oil) & $3.26^{\mathrm{a}}$ & $2.41^{\mathrm{a}}$ & $1.84^{\mathrm{a}}$ & $1.10^{\mathrm{a}}$ & $1.27^{\mathrm{ab}}$ \\
\hline F value (4 d.f.) & 0.14 & 2.27 & 2.14 & 11.36 & 13.24 \\
Treatment & $(\mathrm{P}=\mathrm{n.s.})$ & $(\mathrm{P}=\mathrm{n} . \mathrm{s})$. & $(\mathrm{P}=$ n.s. $)$ & $(\mathrm{P}<0.001)$ & $(\mathrm{P}<0.001)$ \\
F value (5 d.f.) & 0.57 & 0.77 & 0.83 & 0.54 & 0.51 \\
Block & $(\mathrm{P}=$ n.s. $)$ & $(\mathrm{P}=$ n.s. $)$ & $(\mathrm{P}=$ n.s. $)$ & $(\mathrm{P}=\mathrm{n} . \mathrm{s})$. & $(\mathrm{P}=$ n.s. $)$ \\
\hline
\end{tabular}

